\title{
Knowledge Application and Improvement Ideas for In-service Social Work Professionals
}

\author{
Zhenxin Li* \\ Jiangsu Social Work Association, Nanjing 210008, Jiangsu Province, China \\ *Corresponding author: Zhenxin Li, lzx18205153063@163.com
}

\begin{abstract}
Social work professionals are an indispensable force for building a harmonious socialist society as well as strengthening and innovating social management. This article analyzed the salary, job satisfaction, and knowledge application of social work professionals in Nanjing (NJ) by means of a survey questionnaire and found that although most professional social workers are relatively satisfied with their jobs in addition to the effective application of their knowledge, a certain percentage of the respondents reported that the knowledge that they had learned at school were not consistent with the actual needs of work, which affected their income levels and job satisfactions. For this reason, it is suggested that a variety of measures should be taken to improve the quality of professional education of social work and enhance the competitiveness as well as the recognition of the social work profession.
\end{abstract}

Keywords: Social work; Knowledge application; Job satisfaction

Publication date: July 2021; Online publication: July 30, 2021

\section{Research background}

Social work professionals refer to those specialized personnel who have certain professional knowledge and skills for social work and directly provide social services in the fields of social welfare, social assistance, charity, community building, marriage and family, mental health, rehabilitation of the disabled, education counseling, employment and employee assistance, crime prevention, drug control and rehabilitation, correction assistance and education, population and family planning, dispute mediation, as well as emergency response. Social work professionals are an indispensable force for building a harmonious socialist society while strengthening and innovating social management. Specifically, social work professionals undertake certain important tasks of social governance and services where they play a very important role in dealing with social contradictions, resolving social problems, safeguarding fairness and justice, as well as keeping social stability.

Whether social work professionals can assume unique social functions depend on the use and allocation of social work professionals while on the other hand, they are restricted by the professional education level of social work. In order to gain an in-depth understanding of the ability and quality as well as the work adaptation of social work professionals, a survey questionnaire had been conducted in NJ, China. Through the survey, the work situation of social work professionals was obtained where it reflected some problems that required improvements in the professional education of social work.

\section{Status analysis of social work professionals}

A total of 1,000 copies of questionnaires were distributed in this survey. A thousand copies were collected back with a response rate of $100 \%$ of which 940 copies were valid. From the survey, the number of male respondents was 245 , accounting for $26.1 \%$ and the number of female respondents was 695 , accounting for 
73.9\%. In terms of age distribution, there were 445 respondents under the age of 30, accounting for $47.3 \%$, 244 respondents between 30 to 40 years old, accounting for 26\%, 179 respondents between the age of 40 to 50 , accounting for $19 \%$, and 72 respondents over the age of 50, accounting for $7.7 \%$, showing that social workers are generally younger. In terms of educational background, the number of respondents with primary school education was $2(0.2 \%), 24(2.6 \%)$ respondents with junior high school education, 100 (10.6\%) respondents with high school education, 32 (3.4\%) respondents with technical secondary school/secondary vocational school/secondary normal school education, 346 (36.8\%) respondents with junior college education, 417 (44.4\%) respondents with undergraduate education, and 19 (2\%) respondents with master's education or above. In terms of work, the work areas of social work professionals in NJ were mainly distributed in the fields of community building, social assistance, social welfare, family planning, employment services, judicial corrections, etc. There were also a small number of social work professionals working in special care and placement, charity, disaster mitigation and relief, medical care and health, family life services, and youth affairs. There were relatively few social workers in the fields of protection of women's rights and interests, protection of employees' rights and interests, as well as education counseling (see Table 1).

Table 1. Distribution of the work fields of social work professionals in NJ

\begin{tabular}{lcc}
\hline Work field & Number of respondents & Percentage \\
\hline Social welfare & 89 & 9.5 \\
Social assistance & 171 & 18.3 \\
Community building & 271 & 29.0 \\
Special care and placement & 15 & 1.6 \\
Charity & 12 & 1.3 \\
Disaster mitigation and relief & 13 & 1.4 \\
Family life services & 12 & 1.3 \\
Education counseling & 8 & 0.9 \\
Judicial correction & 42 & 4.5 \\
Employment services & 56 & 6.0 \\
Medical care and health & 20 & 2.1 \\
Family planning & 77 & 8.3 \\
Protection of employees' rights and interests & 4 & 0.4 \\
Youth affairs & 18 & 1.9 \\
Protection of women's rights and interests & 3 & 0.3 \\
Others & 123 & 13.2 \\
\hline Total & 934 & 100 \\
\hline
\end{tabular}

\subsection{Analysis of job satisfaction}

In general, the existing social work professionals in $\mathrm{NJ}$ are satisfied with their jobs where the cumulative percentage of "highly satisfied" and the level above it is $62.6 \%$, the valid percentage of "generally satisfied" is $30.4 \%$, the valid percentage of "less satisfied" is $5.9 \%$, and the valid percentage of "very dissatisfied" is $1.1 \%$ (see Table 2). Most of the respondents who expressed satisfaction come from the community while social workers in social organizations and social work service institutions are relatively less satisfied with their jobs. In the ranking of factors that lead to job dissatisfaction, "low salary" ranked first where 346 
respondents chose this factor, accounting for $36.8 \%$ followed by "poor social recognition" which was chosen by 181 respondents, accounting for $19.3 \%$, and "no future of the job" ranked the third place where 195 respondents chose this factor, accounting for $20.7 \%$. In terms of the views on turnover of social work professionals, "low salary" was the most chosen one by the social workers, followed by "complicated and overloaded work," and "no prospect for career development" which ranked third where a total of 434 respondents chose it, accounting for $46.2 \%$. This suggested that the current policy environment in NJ is conducive to the development of talents, but it needs to be further improved in terms of the salary system and working conditions in social organizations and social work service institutions.

Table 2. Job satisfaction of the social work professionals in NJ

\begin{tabular}{lcc}
\hline Degree of satisfaction & Number of respondents & Percentage \\
\hline Very satisfied & 144 & 15.3 \\
Highly satisfied & 445 & 47.3 \\
Generally satisfied & 286 & 30.4 \\
Less satisfied & 55 & 5.9 \\
Very dissatisfied & 10 & 1.1 \\
\hline Total & 940 & 100 \\
\hline
\end{tabular}

In terms of job position setting, 865 respondents thought that their job responsibilities were clear and definite, accounting for $92 \%$. In terms of exerting expertise, "fully exerted" was chosen by 96 respondents, accounting for $10.2 \%$, "highly exerted" was chosen by 441 respondents, accounting for $46.9 \%$, "less exerted" was chosen by 343 respondents, accounting for $36.5 \%$, and "insufficiently exerted" was chosen by 42 respondents, accounting for $4.5 \%$ while "difficult to exert" was chosen by only 18 respondents, accounting for $1.9 \%$, indicating that the knowledge and skills learned by social work professionals can be better used in their work position. In terms of the building of employee expertise mechanism, $42.4 \%$ of the institutions have not established a mechanism for employees to exert their expertise and display their abilities (see Table 3).

Table 3. Establishment of a mechanism for employees to exert their expertise and display their abilities

\begin{tabular}{lcc}
\hline Establishment of a mechanism & Number of respondents & Percentage \\
\hline Yes & 178 & 19.0 \\
Basically established & 363 & 38.6 \\
No & 399 & 42.4 \\
\hline Total & 940 & 100 \\
\hline
\end{tabular}

\subsection{Analysis of salary and welfare}

The survey results showed that the annual salary for most social workers is mainly in the range of RMB 25,000 to RMB35,000 where 395 respondents were in that category, accounting for $42 \%$. This salary level is relatively low. A cumulative percentage of $24.6 \%$ accounted for social workers with an annual income of more than RMB 35,000 while 75.4\% accounted for social workers with an annual income of less than RMB 35,000 (see Table 4). This shows that the annual salaries of social workers in NJ are generally low, and they are facing major survival problems. This may also be the main reason for the turnover of social 
work professionals.

Table 4. Social work income level in the previous year

\begin{tabular}{lcc}
\hline Income level & Number of respondents & Percentage \\
\hline RMB 7000 and below & 57 & 6.1 \\
RMB 7000-15000 & 80 & 8.5 \\
RMB 15000-25000 & 176 & 18.7 \\
RMB 25000-35000 & 395 & 42.1 \\
More than RMB 35000 & 231 & 24.6 \\
\hline Total & 939 & 100 \\
\hline
\end{tabular}

According to the evaluation on the respondents' salary levels, 481 respondents felt that their income is at the lower-middle level in the local area, accounting for $51.2 \%, 261$ respondents felt that their income is at the middle level in the local area, accounting for $27.8 \%$, and only 12 respondents felt that their income is at the upper-middle level in the local area, accounting for $1.3 \%$. The cumulative percentage of respondents who felt that their income is at the lower-middle level and below was $71 \%$ (see Table 5). This suggests that social workers generally feel that their income is lower than the local level in NJ and they subjectively feel that their salary is low.

Table 5. Income level at the local area

\begin{tabular}{lcc}
\hline Income level at the local area & Number of respondents & Percentage \\
\hline Upper-middle & 12 & 1.3 \\
Middle & 261 & 27.8 \\
Lower-middle & 481 & 51.2 \\
Low & 186 & 19.8 \\
\hline Total & 940 & 100 \\
\hline
\end{tabular}

The survey also showed that 407 respondents were not satisfied with their current income level, accounting for $43.3 \%$. Only 20 respondents were very satisfied with their current income level, accounting for $2.1 \%$, and 61 respondents were relatively satisfied, accounting for $6.5 \%$. The cumulative percentage of both was $8.6 \%$ (see Table 6). The data indicate that the salaries of social workers are not high and they are not satisfied with their salaries. Therefore, to solve the problem regarding salaries of social work professionals has become a key issue that needs to be resolved.

Table 6. Satisfaction with current income level

\begin{tabular}{lcc}
\hline Degree of satisfaction & Number of respondents & Percentage \\
\hline Very satisfied & 20 & 2.1 \\
Highly satisfied & 61 & 6.5 \\
Generally satisfied & 299 & 31.9 \\
Less satisfied & 407 & 43.4 \\
Very dissatisfied & 151 & 16.1 \\
Total & 938 & 100 \\
\hline
\end{tabular}




\subsection{Analysis of knowledge application and in-service training}

In terms of application of professional knowledge, most of the respondents felt that a small amount of social work expertise is applied (575 respondents, accounting for 61.2\%) and only 48 respondents chose "job corresponds to specialty," accounting for $5.1 \%$. This indicates that the professional knowledge of social work professionals are mainly acquired in practice. Most social workers felt that their professional knowledge could meet the basic needs of their work where 577 respondents chose it, accounting for $61.4 \%$ (see Table 7). However, under the influence of complex working environment and variable service groups in the future, it is necessary to improve the education and training level of social work professionals.

Table 7. Existing knowledge and skills in meeting job requirements

\begin{tabular}{lcc}
\hline Meeting job requirements & Number of Person & Percentage \\
\hline Completely meet & 102 & 10.9 \\
Basically meet & 577 & 61.4 \\
Not sure & 227 & 24.2 \\
Failed to meet & 33 & 3.5 \\
\hline Total & 939 & 100 \\
\hline
\end{tabular}

Although a training system is available in the industry where 670 respondents, accounting for $71.3 \%$ were engaged in, 381 respondents (accounting for 40.6\%) did not participate in the industry training ( 3 was missing in the system), indicating that the popularization and standardization of industry training need to be strengthened urgently. Nevertheless, the units where social workers work are relatively supportive in their training. 471 leaders supported it, accounting for 50.1\% (see Table 8).

Table 8. Degree of support of unit leaders for training

\begin{tabular}{lcc}
\hline Degree of support & Number of respondents & Percentage \\
\hline Very supportive & 374 & 39.9 \\
Supportive & 471 & 50.3 \\
No intervention & 84 & 9.0 \\
Not supportive & 8 & 0.6 \\
\hline Total & 937 & 100 \\
\hline
\end{tabular}

On the whole, the survey showed that the current social work professionals in NJ were not satisfied with their jobs. The reason that affects their satisfaction is low salary levels on the one hand, but on the other hand, it is also related to the knowledge and skills of most social workers. Most of the respondents felt that only a small amount of professional knowledge is used, and a very small number of respondents chose "job corresponds to specialty" indicating that the professional knowledge obtained by social work professionals in their school education are disjoint from practical needs and applied knowledge are mainly acquired in practice. Therefore, it is necessary to improve the application levels of education of social work professionals.

\section{Ideas for cultivation of social work professionals}

Based on the findings of the survey, the following improvement ideas are proposed: 
Firstly, the cultivation orientation of social work professionals should be focused on cultivating firstclass applied talents. Regardless of being a social work undergraduate or a master's degree holder, they should be acknowledged as applied talents who have the ability to carry out projects and solve problems. To this end, it is necessary to strengthen the ability to apply professional theoretical knowledge of social work in practice as well as the training of social work-related knowledge and skills including community service capabilities, psychological counseling knowledge and skills, public health emergency response capabilities, and so on in order to provide first-class specialized applied talents who truly love the profession of social work for the development of the society.

Secondly, improving the talent promotion mechanism based on job development. There is a need to absorb the experiences of advanced countries or regions and actively develop social work positions based on service objects. To this end, priority can be given to setting up positions such as social work for the aged, disabled, and children's education while incorporating them into the proportion of position setting. In addition, overall management should be conducted, and standards should be formulated for positions in social work organizations. These standards should then be taken as an important basis for internal flow of talents and salary management.

Thirdly, improving the talent introduction mechanism in the interaction between government and grassroot organizations. For the introduction of social work professionals, recruitment is mainly adopted. In view of the serious loss of social work professionals in many organizations and the lack of stability in retention of existing social work professionals in the future, it is suggested that there should be continuous improvement to the introduction mode of social work talents in colleges and universities. On the other hand, the mechanism of interaction between the government and grass-root organizations should be made used to realize the flow of talents between the government, social work organizations, and the society. Through the flow of talents, the stability of social work professional teams can be achieved.

\section{Disclosure statement}

The author declares that there is no conflict of interest.

\section{References}

[1] Shen R, 2011, Cultivating and Bringing up A Great Team of Social Work Professionals. Chinese Public Administration, 3.

[2] 2011, Opinions on Strengthening the Building of Professionals in Social Work, China Society News, 4th edition.

[3] Chang W, 2013, Research on Current Status of Social Work Team Building - Taking NJ Analysis as an Example. Modern Women (Late), 10.

[4] Li N, 2016, Analysis and Countermeasures of Current Status of the Building of Social Work Professionals in Hebei Province. Problems and Suggested Solutions, 3.

[5] Wang D, 2011, Experience and Prospects on Social Work Professional Team Building. Social Work (Practical Edition), 6. 